\title{
Clonidine versus other adjuncts added to local anesthetics for pediatric neuraxial blocks: a systematic review and meta-analysis
}

This article was published in the following Dove Press journal: Journal of Pain Research

\author{
Yang Yang ${ }^{1,2}$ \\ Ling-Yu Yu ${ }^{3}$ \\ Wen-Sheng Zhang ${ }^{1,2}$ \\ 'Laboratory of Anesthesia and \\ Critical Care Medicine, Translational \\ Neuroscience Centre, West China \\ Hospital, Sichuan University, \\ Chengdu, People's Republic of China; \\ ${ }^{2}$ Department of Anesthesiology, West \\ China Hospital, Sichuan University, \\ Chengdu, People's Republic of China; \\ ${ }^{3}$ Department of Otolaryngology- \\ Head and Neck Surgery, West China \\ Hospital, Sichuan University, Chengdu, \\ People's Republic of China
}

Background: Clonidine is a common adjunct to local anesthetics for pediatric neuraxial block; however, the pros and cons between clonidine and other adjuncts remain unclear. Thus, we performed this meta-analysis of randomized controlled trials to assess the efficacy and adverse effects between clonidine and other adjuncts added to local anesthetics.

Materials and methods: The systematic search, data extraction, critical appraisal, and pooled analysis were performed according to the Preferred Reporting Items for Systematic Reviews and Meta-Analyses (PRISMA) statement. Randomized controlled studies were searched in Cochrane (to present), Medline (1946 to present), Embase (1974 to present), and Biosis (1995 to present). Relative risks (RRs), standard mean difference (SMD), and associated CIs were calculated using RevMan statistical software to assess continuous and dichotomous data. Heterogeneity in studies was measured by forest plots and $I^{2}$ values. Subgroup analysis was performed for continuous and dichotomous variables, while meta-regression was applied for continuous data with high $I^{2}$ values.

Results: A total of 15 randomized controlled studies met the inclusion criteria. There was a longer duration of postoperative analgesia in the clonidine group than for other adjuncts ( $\mathrm{SMD}=1.54, p=0.005, l^{2}=96 \%$ ). The number of patients requiring rescue analgesia was lower in the clonidine group without the addition of epinephrine $\left(\mathrm{RR}=0.55, p=0.0002, I^{2}=0\right)$, while the $\mathrm{RR}$ for the comparison with epinephrine was significant $(p=0.62, P=95 \%$ ). The duration of motor block was longer in the clonidine group (mean difference $[\mathrm{MD}]=1.06, p<0.00001, P^{2}=0$ ). The clonidine group also had a lower incidence of postoperative nausea and vomiting (PONV; $\mathrm{RR}=0.49, p<0.00001, I^{2}=0$ ). Postoperative bradycardia, hypotension, and urinary retention were not significantly different between clonidine and other adjuncts $(p>0.05)$.

Conclusion: Clonidine, compared with other adjuncts, added to local anesthetics for neuraxial block, provides a longer duration of postoperative analgesia with lower incidence of PONV. However, the duration of motor block may also be prolonged by clonidine.

Keywords: clonidine, adjuncts, pediatrics, neuraxial block

\section{Introduction}

As the cornerstone of postoperative analgesia in pediatric patients, regional anesthesia, especially single-dose neuraxial block anesthesia, has been widely used in young children as well as high-risk ex-premature infants and neonates. ${ }^{1,2}$ However, with a relatively short duration of 4-6 h of postoperative analgesia with local anesthetics (LAs), the most severe pain in the first 24-72 $\mathrm{h}$ can hardly be covered. Thus, adjuncts such as clonidine, ketamine, morphine, and dexmedetomidine have been used in combination with LAs to prolong the duration of postoperative analgesia.
Correspondence: Wen-Sheng Zhang Laboratory of Anesthesia and Critical Care Medicine, Translational Neuroscience Center, West China Hospital, Sichuan University, 37 Guo Xue Xiang, Chengdu 61004I, Sichuan, People's Republic of China

Tel +862885164040

Email zhang_ws@scu.edu.cn 
Clonidine, an $\alpha-2$ agonist, applied from systemic to regional anesthesia, is a common additive to LAs in pediatric neuraxial block. To the best of our knowledge, although the efficacy and safety of clonidine compared with LAs alone have been demonstrated in several meta-analyses, ${ }^{3-5}$ new adjuncts such as neostigmine, dexmedetomidine, and midazolam have not yet been compared with clonidine. Thus, the aim of this review was to assess and compare the efficacy and safety between clonidine and other adjuncts to LAs in neuraxial block in pediatric surgeries.

\section{Materials and methods}

This meta-analysis was performed according to the criteria of the Preferred Reporting Items for Systematic Reviews and Meta-Analyses (PRISMA) statement.

\section{Search strategy}

Two authors (YY and LYY) independently performed systematic research according to the current recommendations of the Cochrane collaboration: central register of controlled trials of the Cochrane library (to present), Medline (1946 to present), Embase (1974 to present), and Biosis (1995 to present). There were no language restrictions in terms of article or type of publication. The reference of key English articles retrieved was manually searched concerning for potential relevant publication.

\section{Selection criteria}

Two authors (YY and LYY) screened the retrieved articles according to the following criteria to exclude irrelevant studies by scanning the title and abstracts:

1. Population: children presenting for neuraxial blocks (spinal anesthesia, epidural anesthesia, and caudal anesthesia) younger than 18 years old

2. Interventions and controls: use of clonidine with LAs versus alternative adjunct with LAs or use of clonidine and alternative adjunct with LAs versus alternative adjunct with LAs without clonidine. Alternative adjuncts such as morphine, ketamine, dexmedetomidine, and fentanyl were considered, while types of LAs included ropivacaine, bupivacaine, and lidocaine

3. Design: all randomized, quasi-randomized, published, and unpublished controlled clinical studies

4. Outcomes:

a. Efficacy (duration of postoperative analgesia and requiring rescue analgesia)

b. Adverse effects (postoperative nausea and vomiting [PONV], motor block)
The exclusion criteria were as follows:

1. Studies based on patients undergoing general anesthesia or use of clonidine as systemic intravenous adjunct during neuraxial block

2. Studies based on patients undergoing continuous neuraxial block

3. Nonrandomized studies

4. Case reports, letters, reviews, and meta-analysis

5. Articles without accessible data

\section{Data extraction}

Two authors (YY and YLY) independently read the full text to decide the selective studies according to the inclusion and exclusion criteria. The parameters for the extraction of raw data were as follows: title, main authors, year of publication, the dose and type of LAs, the dose and type of adjuncts added to LAs, the dose and type of postoperative rescue analgesia, and outcomes. Then, the primary and secondary outcomes were extracted: first time to rescue analgesia, the total number of requirements of rescue analgesia, sedation score, and the incidence of PONV. The reviewer tried to contact the authors of included studies for raw data if the continuous data were not represented as mean and SD; if the authors failed to reply, data were changed by algorithms. ${ }^{6}$ For statistical analysis, outcomes were entered into RevMan 5.3 provided by the Cochrane collaboration. Any differences at any stage were resolved by consulting a third author (WSZ).

\section{Definition of relevant outcome data}

The duration of postoperative analgesia, the number of patients requiring rescue analgesia, and the total number of postoperative rescue requirements were defined as the time from neuraxial injection until the first requirement for rescue analgesia, which was the most important primary outcome. Pain assessment was performed by a different score system; however, the pain threshold could be considered to be equivalent according to a recent Cochrane review. ${ }^{7}$

\section{Critical appraisal}

Two authors (YY and LYY) performed the critical appraisal by the Cochrane risk-of-bias tool. The standards for appraisal were classified as low risk, unclear, and high risk considering the following: random allocation, concealment, blinding of participants and outcome assessment, incomplete outcome, selective reporting, and other bias. The quality of evidences was evaluated by the GradePro version 3.6.1. 


\section{Statistical analyses}

The duration of postoperative analgesia was calculated by standard mean differences (SMDs) with different scale (minute versus hour), mean differences (MDs) with the same scale, and associated $95 \% \mathrm{CI}$ in the random-effects model. The relative risk (RR) and its $95 \%$ CI were calculated for dichotomous data in the fixed-effects model without heterogeneity. Statistical heterogeneity was calculated by $l$ test, and if the $I^{2}$-value was more than $30 \%$, a random-effects model was adopted for pooling results. To further investigate the sensitivity and heterogeneity, subgroup analysis was applied for categorical and dichotomous data, while meta-regression was performed for continuous data; the meta-regression analysis was conducted in stata14.0 (IBM Corporation, Armonk, NY, USA). Sensitivity analysis was performed by evaluating the methodical quality of included studies (low risk, unclear, and high risk). Potential publication biases were assessed by using the funnel plot analysis.

\section{Results}

As shown in Figure 1, a total of 246 studies were identified as relevant studies; then, 104 studies were excluded for duplication. After further screening for titles and abstracts, 116 studies were eliminated as they did not meet the inclusion criteria; subsequently, 26 articles were selected for further full-text analysis. Finally, 15 studies with randomized controlled trial (RCT) design that investigated 961 children in total were included in this meta-analysis; of these, 14 studies investigated the efficacy of caudal block, while only one study used spinal anesthesia. The characteristics of all included studies are presented in Table 1. Among all studies, pediatric patients undergoing urogenital, perineal, lower limb, and upper and infra-umbilical surgeries were randomly assigned to either clonidine or other adjunct group. Bupivacaine was used in 12 articles $(0.166 \%, 0.2 \%$, and $0.25 \%)$, of which only one study using $0.25 \%$ bupivacaine mixed with $1 \%$ lidocaine; in addition, ropivacaine was used in three studies in our research. Additives added in control groups were as follows: six studies with fentanyl, two studies with ketamine, two studies with morphine, one study with hydromorphone, one study with neostigmine, one study with s-ketamine, one study with midazolam, one study with dexmedetomidine, and one study with dexamethasone. The induction and maintenance of anesthesia were performed by inhalational anesthetics in 12 studies, while two studies used induction with propofol, one with thiopental, and only one study used either volatile anesthetic or propofol. Clonidine was applied in four doses $(1,1.5,2$, and $3 \mu \mathrm{g} / \mathrm{kg})$ with a common dose of 1 or $2 \mu \mathrm{g} / \mathrm{kg}$ throughout all studies.
Two authors (YY and YLY) discussed the risks of bias in all the included studies as being low risk, unclear, and high risk. Six studies presented unclear risk as they did not show the method of generating randomization and allocation concealment, and one study presented high risk as single blinding was performed on children only.

\section{Duration of postoperative analgesia}

A total of 15 studies included 961 patients reported the duration of postoperative analgesia, of which three studies were reported as median and CI, meanwhile one study defined the time as administration of drug (induction or block) on the Face, Legs, Activity, Cry, Consolability (FLACC) scale as $>4$, meanwhile one study was excluded at this stage because the definition of postoperative analgesia in which included the time of performing anesthesia. The duration of postoperative analgesia was prolonged in the clonidine group with significant heterogeneity ( $p=0.0005, I^{2}=96 \%$; Figure 2$)$; therefore, subgroup analysis was performed to analyze the differences between groups, including type of LAs or other adjuncts, dosage of clonidine, and addition of epinephrine. However, effects varied and the mentioned subgroups did not demonstrate stratification for the high heterogeneity: in the subgroup of clonidine dosage, $1 \mu \mathrm{g} / \mathrm{kg}$ clonidine addicted to LAs showed a longer analgesic time than other doses $(p=0.02$, $\left.I^{2}=96 \%\right)$. As only one study included added epinephrine to LA in both groups, the result only showed a high heterogeneity in the group without epinephrine ( $p=0.004, I^{2}=95 \%$ ). In the subgroup analyses, different types of adjuncts compared with the clonidine, fentanyl, and ketamine groups showed shorter duration of analgesia, and pooling results showed a prolonged time in the clonidine group ( $\left.p<0.0001, I^{2}=95 \%\right)$. The subgroup analysis of different LAs showed that ropivacaine had a longer analgesic duration than bupivacaine $\left(p=0.0005, I^{2}=\right.$ $99 \%$ ). Despite using meta-regression, we were still unable to determine the relationship between duration of postoperative analgesia and subgroup stratification. Thus, clonidine could provide longer duration of postoperative analgesia; however, the effects of clonidine varied significantly, and the factors we hypothesized earlier could not explain the heterogeneity.

\section{Number of patients requiring rescue analgesia}

Four studies including 181 patients reported on the number of rescue analgesia required. The results showed that clonidine, as compared with other adjuncts, had no statistical significance on the analgesia required ( $p=0.06, I^{2}=78$; Figure 3 ). Owing to the high $I^{2}$, a subgroup analysis was performed 


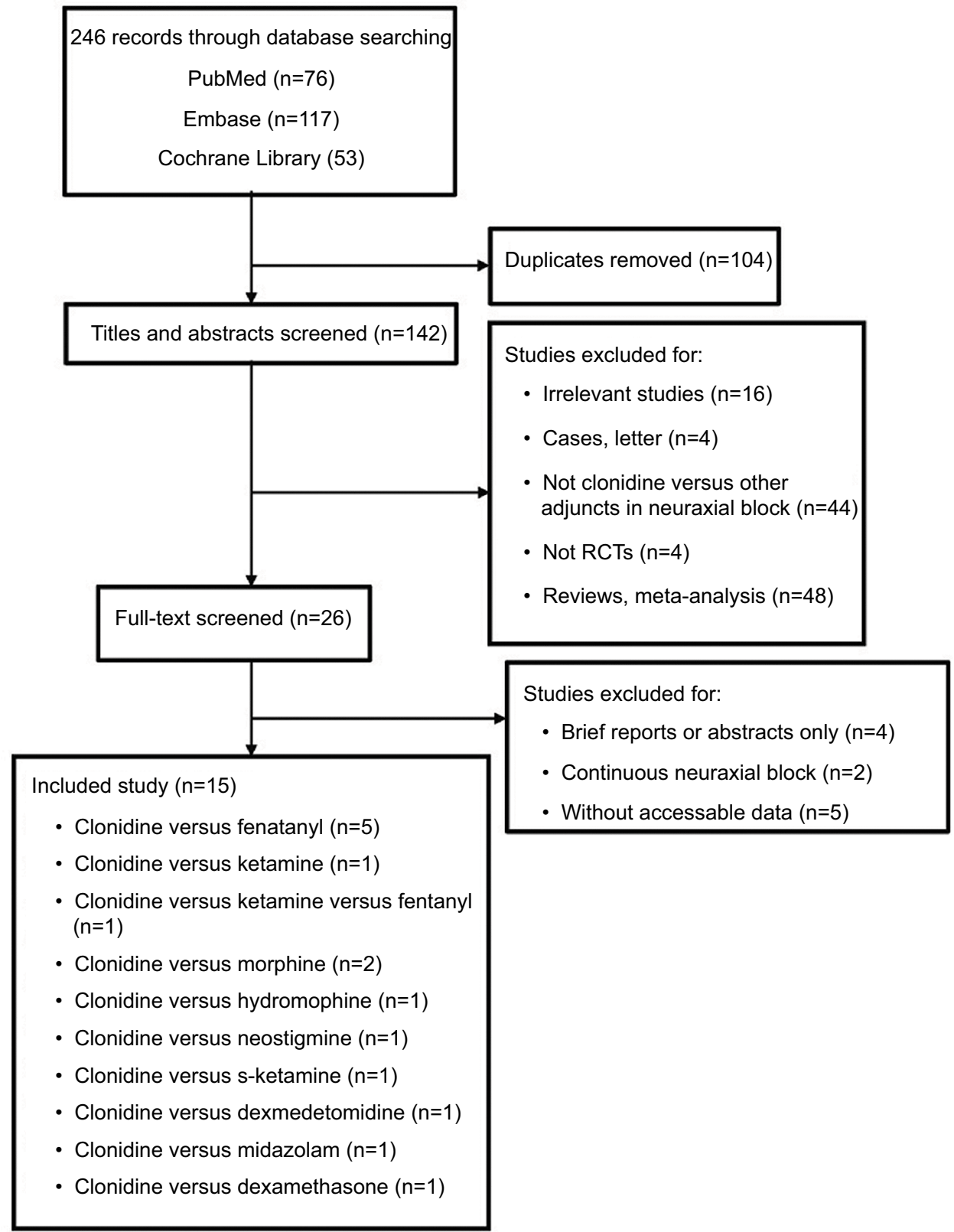

Figure I Literature flowchart.

Abbreviation: RCT, randomized controlled trial.

according to the use of epinephrine, demonstrating the RR of 0.001 between the clonidine group and other adjunct group when added without epinephrine $\left(p=0.003, I^{2}=0\right)$. In the subgroup of adjuncts with epinephrine, there was still high heterogeneity in the two studies included, which may be the sake of LAs used, as Constant et $\mathrm{al}^{8}$ used lidocaine plus bupivacaine, while Fernandes et $\mathrm{a}^{9}{ }^{9}$ used only bupivacaine.

\section{Total number of postoperative rescue requirements}

Three studies reported the number of postoperative analgesia, as the results were only number without SD, instead of a pooled analysis; the description with $p$-value is presented in Table 2 . Compared with clonidine, the ketamine group represented equivalent requirements with no statistical significance, while the morphine group required less rescue analgesia with metamizol, and the midazolam group required more rescue analgesia.

\section{Duration of motor block}

Two studies reporting the duration of motor block, defined as the time interval from caudal block to the first spontaneous movements of leg, showed that a longer regression of motor block was observed with the use of clonidine ( $\mathrm{MD}=0.55$, $p<0.00001, I^{2}=0$; Figure 4). 
Table I Main characteristics of the included studies tested the efficacy of clonidine added to long-lasting LAs in neuraxial blocks

\begin{tabular}{|c|c|c|c|}
\hline Reference & $\begin{array}{l}\text { Type of } \\
\text { anesthesia }\end{array}$ & Treatment (number of patients) & Rescue medication \\
\hline $\begin{array}{l}\text { Ahuja et al, } \\
2015^{19}\end{array}$ & Caudal & $\begin{array}{l}\text { I. Bupivacaine } 0.25 \% \mathrm{I} \mathrm{mL} / \mathrm{kg}+0.9 \% \text { normal saline (20) } \\
\text { 2. Bupivacaine } 0.25 \% \mathrm{I} \mathrm{mL} / \mathrm{kg}+\text { fentanyl I } \mu \mathrm{gg} / \mathrm{kg}(20) \\
\text { 3. Bupivacaine } 0.25 \% \mathrm{I} \mathrm{mL} / \mathrm{kg}+\text { clonidine } 3 \mu g / \mathrm{kg}(20)\end{array}$ & $\begin{array}{l}\text { Paracetamol } 20 \mathrm{mg} / \mathrm{kg} \text { po or } \\
\text { suppo }\end{array}$ \\
\hline $\begin{array}{l}\text { Akbas et al, } \\
2005^{20}\end{array}$ & Caudal & $\begin{array}{l}\text { I. Ropivacaine } 0.2 \% 0.75 \mathrm{~mL} / \mathrm{kg}(25) \\
\text { 2. Ropivacaine } 0.2 \% 0.75 \mathrm{~mL} / \mathrm{kg} \text { + clonidine I } \mu \mathrm{gg} / \mathrm{kg}(25) \\
\text { 3. Ropivacaine } 0.2 \% 0.75 \mathrm{~mL} / \mathrm{kg} \text { + ketamine } 0.5 \mathrm{mg} / \mathrm{kg}(25)\end{array}$ & Paracetamol $15 \mathrm{mg} / \mathrm{kg}$ po \\
\hline $\begin{array}{l}\text { Batra et al, } \\
2010^{21}\end{array}$ & Spinal & $\begin{array}{l}\text { I. Bupivacaine } 8 \% 0.4 \text { or } 0.5 \mathrm{mg} / \mathrm{kg} \text { (I5) } \\
\text { 2. Bupivacaine } 8 \% 0.4 \text { or } 0.5 \mathrm{mg} / \mathrm{kg}+\text { clonidine I } \mu \mathrm{g} / \mathrm{kg}(\mathrm{I} 6) \\
\text { 3. Bupivacaine } 8 \% 0.4 \text { or } 0.5 \mathrm{mg} / \mathrm{kg}+\text { fentanyl I } \mu \mathrm{gg} / \mathrm{kg}(\mathrm{I5}) \\
\text { 4. Bupivacaine } 8 \% 0.4 \text { or } 0.5 \mathrm{mg} / \mathrm{kg} \text { + clonidine I } \mu \mathrm{g} / \mathrm{kg}+\text { fentanyl I } \mathrm{mg} / \mathrm{kg}(\mathrm{I5})\end{array}$ & None \\
\hline $\begin{array}{l}\text { Constant } \\
\text { et al, } 1998^{8}\end{array}$ & Caudal & 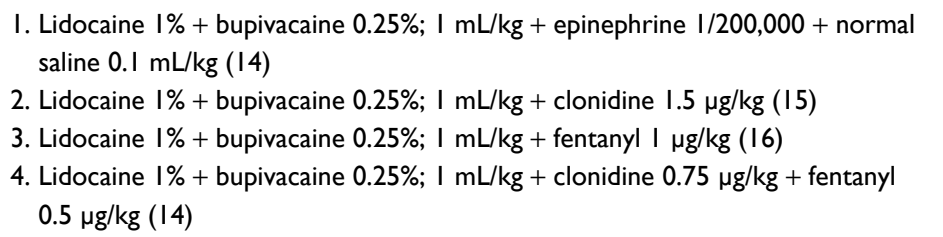 & $\begin{array}{l}\text { Propacetamol } 30 \mathrm{mg} / \mathrm{kg} \mathrm{IV} \\
\text { nalbuphine } 0.2 \mathrm{mg} / \mathrm{kg} \mathrm{IV} \text { if pain } \\
\text { scores remained unchanged } \\
30 \text { min later }\end{array}$ \\
\hline $\begin{array}{l}\text { El-Hennawy } \\
\text { et al, } 2009^{22}\end{array}$ & Caudal & $\begin{array}{l}\text { I. Bupivacaine } 0.25 \% \mathrm{I} \mathrm{mL} / \mathrm{kg}+\text { dexmedetomidine } 2 \mu \mathrm{gg} / \mathrm{kg}(20) \\
\text { 2. Bupivacaine } 0.25 \% \mathrm{I} \mathrm{mL} / \mathrm{kg}+\text { clonidine } 2 \mu \mathrm{m} / \mathrm{kg}(20) \\
\text { 3. Bupivacaine } 0.25 \% \mathrm{I} \mathrm{mL} / \mathrm{kg}+\mathrm{NS}(20)\end{array}$ & Morphine $0.2 \mathrm{mg} / \mathrm{kg}$ im \\
\hline $\begin{array}{l}\text { Fernandes } \\
\text { et al, } 2012^{9}\end{array}$ & Caudal & $\begin{array}{l}\text { I. Bupivacaine } 0.166 \% \text { I mL/kg + epinephrine I:600,000 (20) } \\
\text { 2. Bupivacaine } 0.166 \% \mathrm{I} \mathrm{mL} / \mathrm{kg} \text { + epinephrine I: } 600,000+\text { morphine } 20 \mathrm{\mu g} / \mathrm{kg}(20) \\
\text { 3. Bupivacaine } 0.166 \% \mathrm{I} \mathrm{mL} / \mathrm{kg} \text { + epinephrine } 1: 600,000+\text { clonidine } 1.0 \mu \mathrm{gg} / \mathrm{kg}(20)\end{array}$ & $\begin{array}{l}\text { Metamizol } \\
\text { Ibuprofen } \\
\text { Morphine }\end{array}$ \\
\hline Jamali, $1994^{23}$ & Caudal & $\begin{array}{l}\text { I. Bupivacaine } 0.25 \% \mathrm{I} \mathrm{mL} / \mathrm{kg} \text { + epinephrine } \mathrm{I} / 200,000(\mathrm{n}=15) \\
\text { 2. Bupivacaine } 0.25 \% \mathrm{I} \mathrm{mL} / \mathrm{kg} \text { + clonidine I } \mu \mathrm{g} / \mathrm{kg}(\mathrm{n}=15) \\
\text { 3. Bupivacaine } 0.25 \% \mathrm{I} \mathrm{mL} / \mathrm{kg}(\mathrm{n}=15)\end{array}$ & $\begin{array}{l}\text { Proparacetamol } 100 \mathrm{mg} / \mathrm{kg} \mathrm{IV} \mathrm{or} \\
\text { paracetamol }\end{array}$ \\
\hline $\begin{array}{l}\text { Khatavkar } \\
\text { et al, } 2016^{24}\end{array}$ & Caudal & $\begin{array}{l}\text { I. Ropivacaine } 0.25 \% \text { I mL/kg + fentanyl I } \mu g / \mathrm{kg}(30) \\
\text { 2. Ropivacaine } 0.25 \% \mathrm{I} \mathrm{mL} / \mathrm{kg} \text { + clonidine I } \mu g / \mathrm{kg}(30)\end{array}$ & Paracetamol 15 mg/kg po \\
\hline $\begin{array}{l}\text { Paul et al, } \\
2010^{12}\end{array}$ & Caudal & $\begin{array}{l}\text { I. Bupivacaine } 0.25 \% \mathrm{I} \mathrm{mL} / \mathrm{kg}+\mathrm{NS}(25) \\
\text { 2. Bupivacaine } 0.25 \% \mathrm{I} \mathrm{mL} / \mathrm{kg}+\text { clonidine I } \mu \mathrm{g} / \mathrm{kg}(25) \\
\text { 3. Bupivacaine } 0.25 \% \mathrm{I} \mathrm{mL} / \mathrm{kg}+\text { neostigmine } 2 \mu \mathrm{\mu g} / \mathrm{kg}(25)\end{array}$ & Paracetamol syrup \\
\hline $\begin{array}{l}\text { Ribeiro et al, } \\
201 I^{25}\end{array}$ & Caudal & $\begin{array}{l}\text { I. Bupivacaine } 0.25 \% 0.75 \mathrm{mg} \text { without adrenaline }(\mathrm{I} 0) \\
\text { 2. Bupivacaine } 0.25 \% 0.75 \mathrm{~mL} / \mathrm{kg}+\text { clonidine I } \mu \mathrm{gg} / \mathrm{kg} \text { without adrenaline }(2 \mathrm{I}) \\
\text { 3. Bupivacaine } 0.25 \% 0.75 \mathrm{~mL} / \mathrm{kg}+\mathrm{s}-\mathrm{ketamine} 0.5 \mathrm{mg} / \mathrm{kg} \text { without adrenaline (20) }\end{array}$ & Dipyrone $30 \mathrm{mg} / \mathrm{kg} \mathrm{IV}$ \\
\hline $\begin{array}{l}\text { Sanwatsarkar } \\
\text { et al, } 2017^{26}\end{array}$ & Caudal & $\begin{array}{l}\text { I. Bupivacaine } 0.25 \% \mathrm{I} \mathrm{mL} / \mathrm{kg}(25) \\
\text { 2. Bupivacaine } 0.25 \% \mathrm{I} \mathrm{mL} / \mathrm{kg}+\text { clonidine I } \mu \mathrm{g} / \mathrm{kg}(25) \\
\text { 3. Bupivacaine } 0.25 \% \mathrm{I} \mathrm{mL} / \mathrm{kg}+\text { midazolam } 30 \mu g / \mathrm{kg}(25)\end{array}$ & $\begin{array}{l}\text { Paracetamol loading } 40 \mathrm{mg} / \mathrm{kg} \\
\text { followed by } 20 \mathrm{mg} / \mathrm{kg} 6 \mathrm{~h} \mathrm{v}\end{array}$ \\
\hline $\begin{array}{l}\text { Shukla et al, } \\
2011^{27}\end{array}$ & Caudal & $\begin{array}{l}\text { I. Ropivacaine } 0.25 \% \text { I mL/kg + clonidine } 2 \mu \mathrm{g} / \mathrm{kg}(45) \\
\text { 2. Ropivacaine } 0.25 \% \mathrm{I} \mathrm{mL} / \mathrm{kg}+\text { fentanyl I } \mu \mathrm{g} / \mathrm{kg}(45)\end{array}$ & Paracetamol $10 \mathrm{mg} / \mathrm{kg}$ po \\
\hline $\begin{array}{l}\text { Singh et al, } \\
2012^{28}\end{array}$ & Caudal & $\begin{array}{l}\text { I. Bupivacaine } 0.2 \% \quad 1.25 \mathrm{~mL} / \mathrm{kg}+\text { clonidine } 2 \mu \mathrm{\mu g} / \mathrm{kg}(25) \\
\text { 2. Bupivacaine } 0.2 \% \quad 1.25 \mathrm{~mL} / \mathrm{kg}+\text { morphine } 30 \mu g / \mathrm{kg}(25)\end{array}$ & $\begin{array}{l}\text { Fentanyl I } \mu g / \mathrm{kg} \mathrm{IV} \\
\text { Acetaminophen } 40 \mathrm{mg} / \mathrm{kg} \text { suppo }\end{array}$ \\
\hline $\begin{array}{l}\text { Singh et al, } \\
2011^{29}\end{array}$ & Caudal & $\begin{array}{l}\text { I. Bupivacaine } 0.25 \% 0.75 \mathrm{~mL} / \mathrm{kg}(\mathrm{n}=20) \\
\text { 2. Bupivacaine } 0.25 \% 0.75 \mathrm{~mL} / \mathrm{kg}+\text { clonidine I } \mu g / \mathrm{kg}(\mathrm{n}=20) \\
\text { 3. Bupivacaine } 0.25 \% 0.75 \mathrm{~mL} / \mathrm{kg}+\text { ketamine } 0.5 \mathrm{mg} / \mathrm{kg}(20) \\
\text { 4. Bupivacaine } 0.25 \% 0.75 \mathrm{~mL} / \mathrm{kg}+\text { fentanyl I } \mu \mathrm{gg} / \mathrm{kg}(\mathrm{n}=20)\end{array}$ & Paracetamol \\
\hline $\begin{array}{l}\text { Sinha et al, } \\
2016^{30}\end{array}$ & Caudal & $\begin{array}{l}\text { I. Bupivacaine } 0.25 \% 0.5 \mathrm{~mL} / \mathrm{kg}+\text { dexamethasone } 0.1 \mathrm{mg} / \mathrm{kg}(30) \\
\text { 2. Bupivacaine } 0.25 \% 0.5 \mathrm{~mL} / \mathrm{kg} \text { + clonidine I } \mu \mathrm{g} / \mathrm{kg}(30)\end{array}$ & Paracetamol syrup 15 mg/kg po \\
\hline
\end{tabular}

Abbreviations: po, peros; im, intramuscular; NS, normal saline; IV, intravenous injection.

\section{Adverse effects}

With respect to adverse effects in both the clonidine and other adjunct groups, the most common was PONV, reported in 15 studies (RR of 0.49 was higher in the clonidine group; $p<0.00001, I^{2}=0$; Figure 5). Bradycardia was reported in nine studies, with two patients in the clonidine group, three patients in the midazolam group, and two patients in the dexamethasone group, and a lower RR of 0.78 was observed in patients using clonidine ( $p=0.72, I^{2}=26 \%$ ). Hypotension was found in eight studies, while two studies only represented hypotension with a relatively lower $\mathrm{RR}$ in the clonidine group $\left(\mathrm{RR}=0.43, p=0.37, I^{2}=0\right)$. Urinary retention was examined 


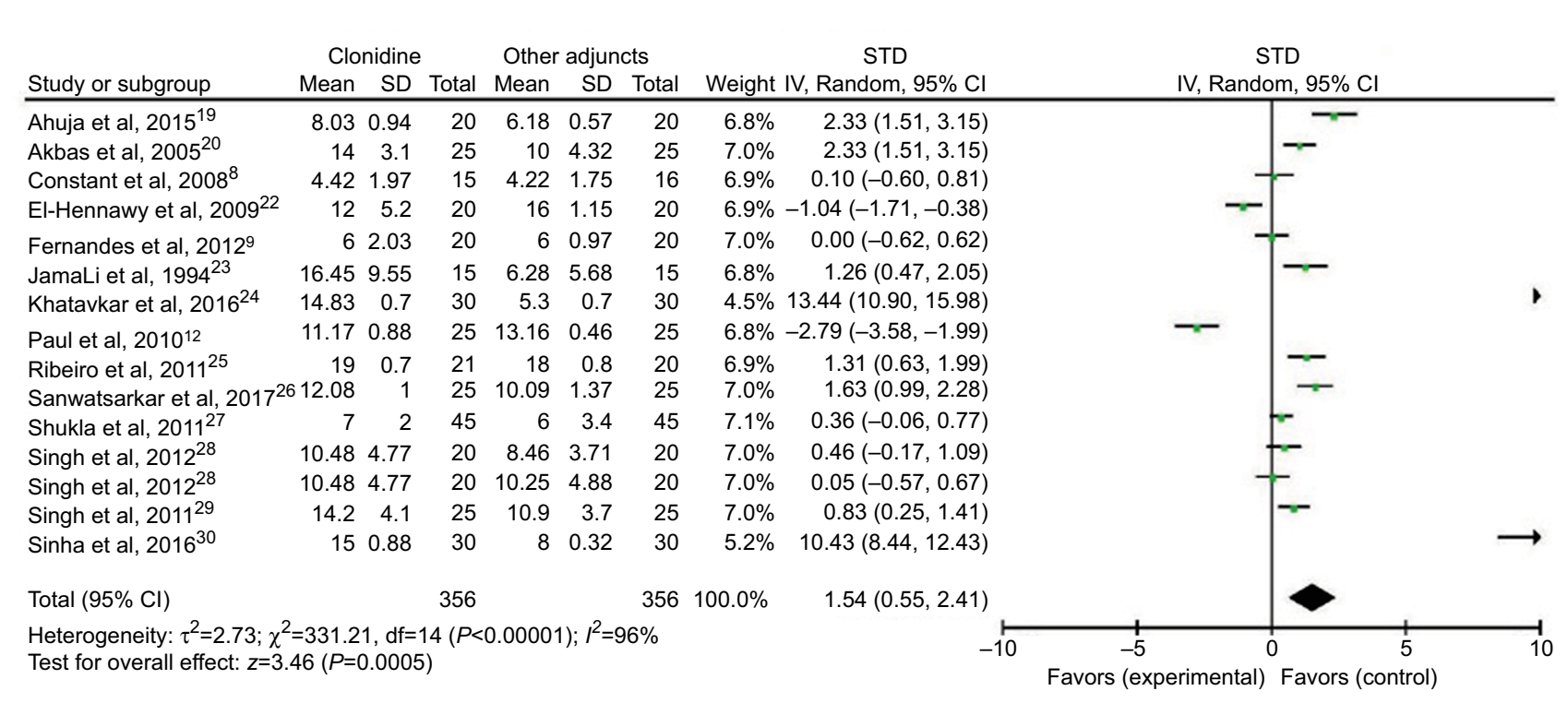

Figure 2 Pooled data assessing the duration between clonidine and other adjuncts added to LAs.

Abbreviations: LAs, local anesthetics; SMD, standard mean difference; IV, intravenous injection.

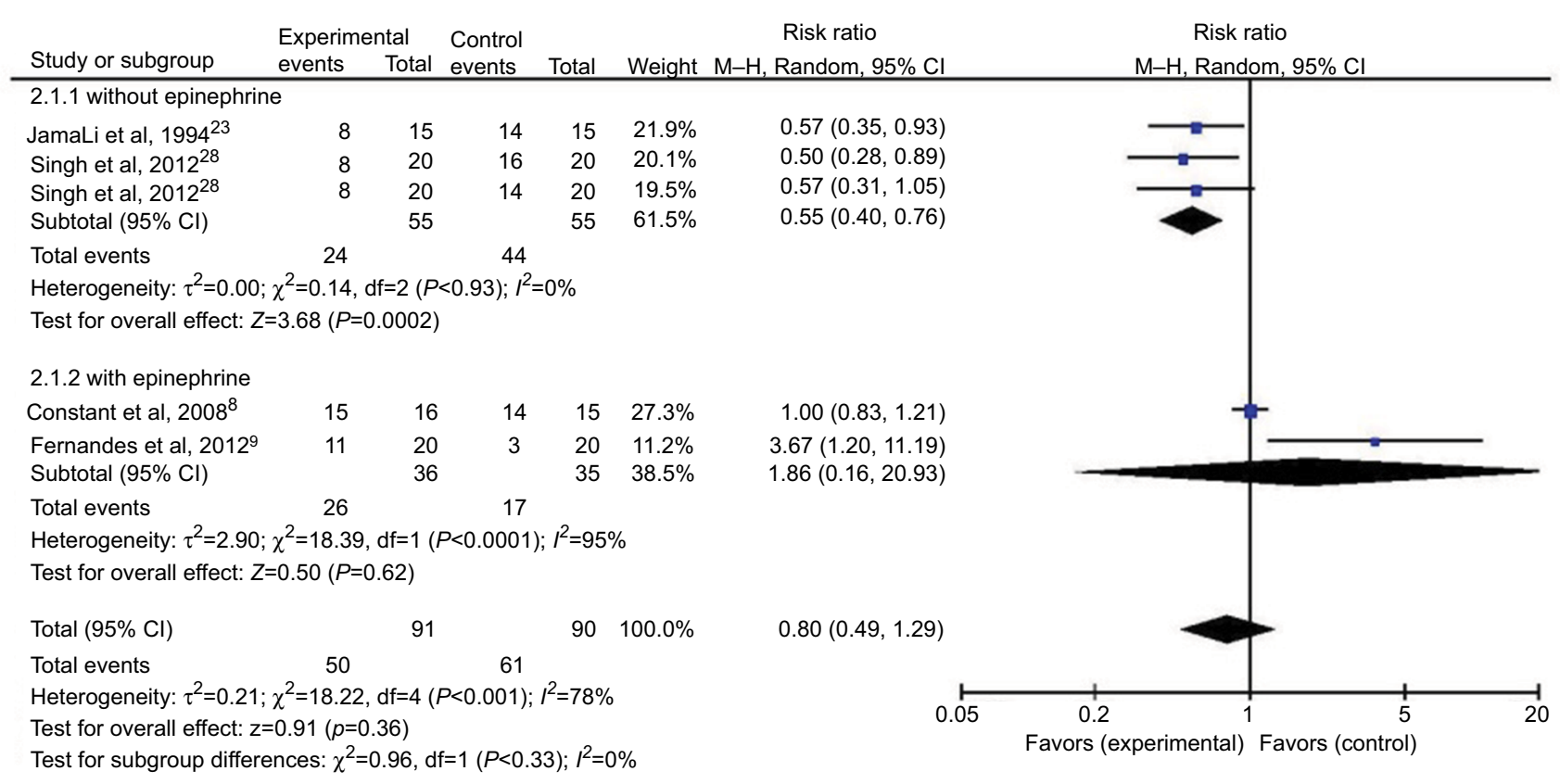

Figure 3 Number of patients requiring a rescue analgesia.

Table 2 Total number of postoperative rescue requirements

\begin{tabular}{|c|c|c|c|c|}
\hline \multirow[t]{2}{*}{ Reference } & \multirow[t]{2}{*}{ Rescue medication } & \multicolumn{2}{|c|}{$\begin{array}{l}\text { Number of postoperative rescue } \\
\text { analgesia }\end{array}$} & \multirow[t]{2}{*}{$p$-value } \\
\hline & & Clonidine & Other adjuncts & \\
\hline Akbas et al, $2005^{20}$ & Paracetamol 15 mg/kg po & 4 & 4 (ketamine) & $>0.05$ \\
\hline \multirow[t]{3}{*}{ Fernandes et al, $2012^{9}$} & Metamizol & 11 & 3 (morphine) & $<0.05$ \\
\hline & lbuprofen & 1 & 0 & $>0.05$ \\
\hline & Morphine & 1 & 0 & $>0.05$ \\
\hline Sanwatsarkar et al, $2017^{26}$ & Paracetamol loading $40 \mathrm{mg} / \mathrm{kg}$ followed by $20 \mathrm{mg} / \mathrm{kg} 6 \mathrm{~h}$ & 48 & 73 (midazolam) & $<0.05$ \\
\hline
\end{tabular}


Clonidine Other adjuncts

MD

MD

Study or subgroup Mean SD Total Mean SD Total Weight IV, Fixed, 95\% Cl

\begin{tabular}{lrrrr} 
Constant et al, $2008^{8}$ & 4.1 & 0.42 & 16 & 3.4 \\
Shukla et al, $2011^{27}$ & 4 & 0.5 & 45 & 3.5 \\
& & \\
Total $(95 \% \mathrm{Cl})$ & \multicolumn{3}{c}{61} \\
Heterogeneity: $\chi^{2}=0.82, \mathrm{df}=1(P=0.36) ; I^{2}=0 \%$ \\
Test for overall effect: $z=5.89(P<0.00001)$
\end{tabular}

$15 \quad 22.9 \% \quad 0.70(0.32,1.08)$

$4577.1 \% 0.50(0.29,0.71)$

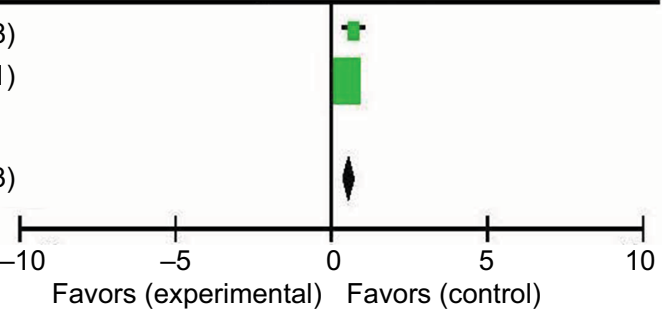

Figure 4 Duration of motor block between clonidine and other adjuncts.

Abbreviation: MD, mean difference; IV, intravenous injection.

$60100.0 \% \quad 0.55(0.36,0.73)$

Favors (experimental) Favors (control)

\begin{tabular}{|c|c|c|c|c|c|}
\hline Study or subgroup & $\begin{array}{l}\text { Clonid } \\
\text { events }\end{array}$ & $\begin{array}{l}\text { ne } \\
\text { Total }\end{array}$ & $\begin{array}{l}\text { Other ad } \\
\text { events }\end{array}$ & $\begin{array}{l}\text { ncts } \\
\text { Total }\end{array}$ & Weight \\
\hline Ahuja et al, $2015^{19}$ & 0 & 20 & 0 & 20 & \\
\hline Akbas et al, $2005^{20}$ & 5 & 25 & 7 & 25 & $8.2 \%$ \\
\hline Constant et al, $2008^{8}$ & 0 & 16 & 4 & 16 & $5.4 \%$ \\
\hline El-Hennawy et al, $2009^{22}$ & 8 & 20 & 9 & 20 & $10.6 \%$ \\
\hline Fernandes et al, $2012^{9}$ & 1 & 20 & 7 & 20 & $8.2 \%$ \\
\hline JamaLi et al, $1994^{23}$ & 1 & 15 & 0 & 15 & $0.6 \%$ \\
\hline Khatavkar et al, $2016^{24}$ & 1 & 30 & 2 & 30 & $2.3 \%$ \\
\hline Paul et al, $2010^{12}$ & 2 & 25 & 4 & 25 & $4.7 \%$ \\
\hline Ribeiro et al, $2011^{25}$ & 0 & 20 & 0 & 20 & \\
\hline Sanwatsarkar et al, $2017^{26}$ & 0 & 25 & 1 & 25 & $1.8 \%$ \\
\hline Shukla et al, $2011^{27}$ & 0 & 45 & 8 & 45 & $10.0 \%$ \\
\hline Singh et al, $2012^{28}$ & 0 & 20 & 2 & 20 & $2.9 \%$ \\
\hline Singh et al, $2012^{28}$ & 0 & 20 & 1 & 20 & $1.8 \%$ \\
\hline Singh et al, $2011^{29}$ & 1 & 25 & 3 & 25 & $3.5 \%$ \\
\hline Vetter et al, $2007^{31}$ & 10 & 20 & 16 & 20 & $18.8 \%$ \\
\hline Vetter et al, $2007^{31}$ & 10 & 20 & 18 & 20 & $21.1 \%$ \\
\hline Total $(95 \% \mathrm{Cl})$ & & 367 & & 365 & $100.0 \%$ \\
\hline Total events & 39 & & 82 & & \\
\hline \multicolumn{6}{|c|}{$\begin{array}{l}\text { Heterogeneity: } \chi^{2}=10.90, \mathrm{df}=13(P<0.62) ; l^{2}=0 \% \\
\text { Test for overall effect: } z=4.71(P=0.00001)\end{array}$} \\
\hline
\end{tabular}

Figure 5 Incidence of PONV between clonidine and other adjuncts.

Abbreviation: PONV, postoperative nausea and vomiting.

in seven studies and found in three out of the seven studies, and a lower RR of 0.21 was seen in the clonidine group $\left(p=0.09, I^{2}=0\right)$. Respiratory depression, defined as peripheral capillary oxygen saturation $\left(\mathrm{SpO}_{2}\right)<95 \%$, was assessed in 12 studies while only one study of 12 studies found. Moreover, one patient in the midazolam and clonidine groups suffered from respiratory depression. Pruritus was assessed in five studies, two of which documented the occurrence of pruritus as an adverse event, and the incidence of the clonidine group showed a lower RR of $0.43\left(p=0.37, I^{2}=0\right)$. One study assessed hallucination, while another one assessed neurological impairment, and no patient was found with the mentioned adverse effects.
Risk ratio Risk ratio M-H, Fixed, 95\% Cl

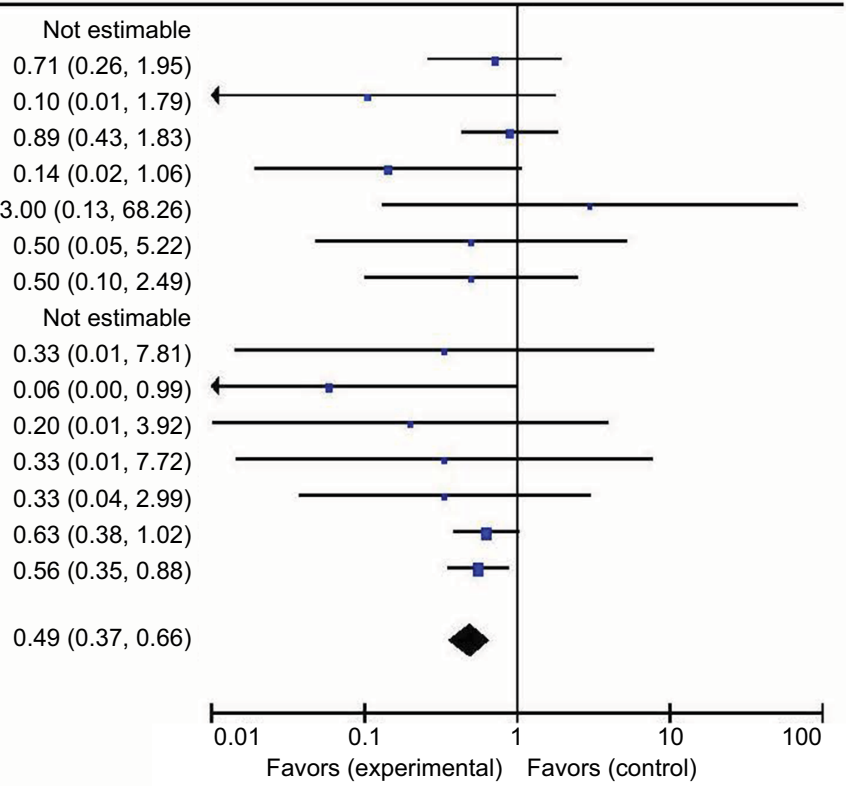

\section{Meta-regression analysis}

A large heterogeneity was found in the duration of postoperative analgesia indicating the existence of study characteristics influencing this variance. Thus, we performed a meta-regression analysis to assess the predictive effect of country, age range, concealment, type of adjuncts, dose range of clonidine, and type of LAs. No parameter was found to have a significant relation with the high heterogeneity in the duration of postoperative analgesia.

\section{Grade quality}

The sensitivity of the study was assessed by GradePro (Table 3). 


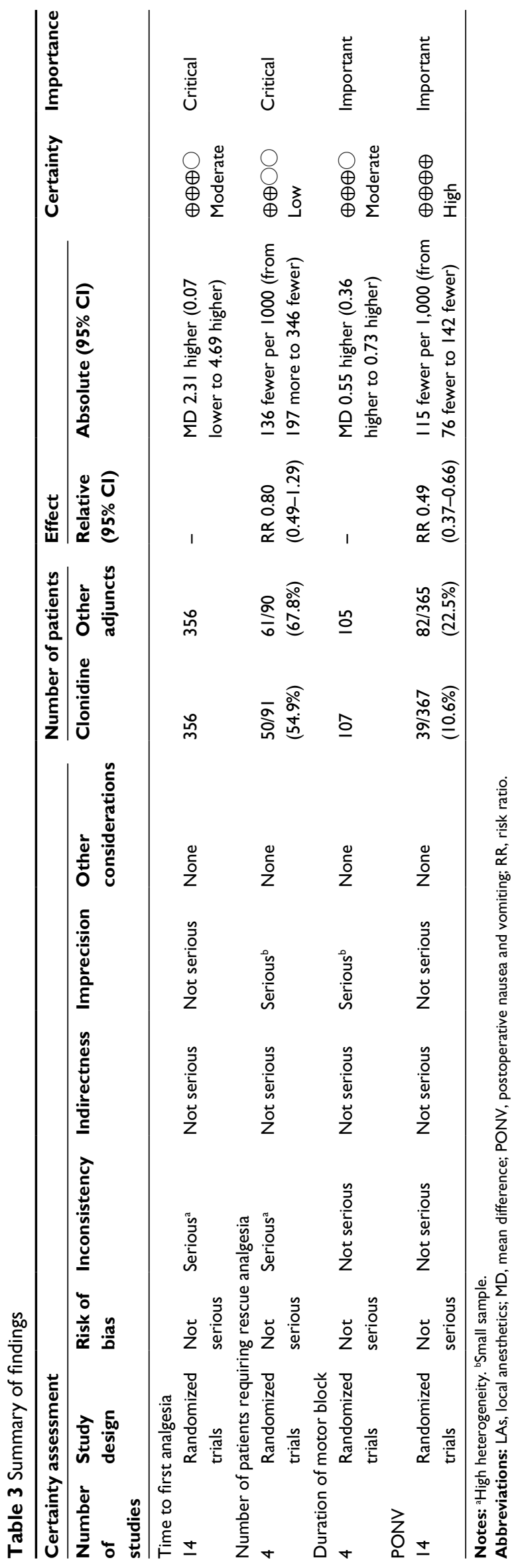

\section{Discussion}

Our systematic review included 15 studies of 961 pediatric patients, wherein we assessed the efficacy and adverse effect between clonidine and other adjuncts added to LAs in neuraxial anesthesia. A longer duration of postoperative analgesia, less number of patients requiring rescue analgesia, and longer regression time of motor block were demonstrated in patients using clonidine. The total number of analgesic requirements in the clonidine group was similar to the ketamine group, while the morphine group reported less, and the midazolam group needs more. In addition, the incidences of adverse effects were relatively lower in the clonidine group, except in the case of a longer motor block.

\section{Efficacy effect}

Clonidine, with the effects of lengthening duration of analgesia, providing better sedation and a lower incidence of PONV has been investigated in a large number of clinical trials and meta-analyses. ${ }^{10,11}$ However, the assessments of efficacy and adverse effects between clonidine and other adjuncts have been controversial. Popping et $\mathrm{al}^{11}$ showed that clonidine can improve the duration of postoperative analgesia only when added into intermediate-acting LAs, implying that the analgesic effects of clonidine with long-acting LAs (such as bupivacaine and ropivacaine) were not superior to using LAs alone. However, our meta-analysis revealed the contrary, in that clonidine could improve the efficacy of long-acting LAs. Paul et a ${ }^{12}$ found that patients in the clonidine group showed a significant longer analgesic duration than those in the bupivacaine group alone and a lesser duration than those in the neostigmine group. Fernandes et $\mathrm{al}^{9}$ reported that clonidine and morphine had a similar effect on the duration of postoperative analgesia, while the number of patients requiring rescue analgesia was higher in the clonidine group, with a low incidence of adverse effects.

We found that the SMD of the duration of postoperative analgesia showed that $1-3 \mu \mathrm{g} / \mathrm{kg}$ clonidine provided longer duration than other adjuncts, while the number of patients requiring rescue analgesia was lower in the clonidine group without epinephrine. The total number of postoperative rescue analgesic administration in the clonidine group was higher than the morphine group, and an equivalent effect was found when compared with ketamine, while lower requirements were investigated when compared with the midazolam group in the current review. In addition, motor block was observed in two studies comparing clonidine with fentanyl, wherein an MD of $0.55 \mathrm{~h}$ was assessed in the clonidine group indicating that clonidine, compared with opioids as an adjunct 
to LA, provides a slightly longer duration of motor block in neuraxial block.

\section{Adverse effects}

In our meta-analysis, PONV was the most common adverse effect encountered in the included studies, and a lower RR of 0.49 was observed in the clonidine group indicating a lower incidence of PONV than other adjuncts currently applied to LAs (Figure 3). Bradycardia was observed in seven out of 421 patients altogether, and a lower RR of 0.78 was assessed in the clonidine group, as was observed in Ansermino et al's report that a high dose of clonidine $(5 \mu \mathrm{g} / \mathrm{kg})$ was associated with increasing severity of sedation and incidence of cardiovascular side effects. ${ }^{13}$ In eight studies that investigate on the incidence of hypotension, there were one, three, and one occurrence of hypotension in patients in the clonidine, fentanyl, and midazolam groups, respectively, and showed a lower RR of 0.43 in the clonidine group. Only one in 12 studies mentioned respiratory depression that was found in one patient in the $1 \mu \mathrm{g} / \mathrm{kg}$ clonidine group and one in the midazolam group, as was demonstrated in studies of preterm infants and neonates, that clonidine may increase the incidence of respiratory depression. ${ }^{14,15}$ Pruritus was observed in patients using clonidine, eight patients each in the morphine, ketamine, dexmedetomidine, and fentanyl groups, while the incidence was relatively high in the morphine group. Seven studies recorded the incidence of urinary retention; no patients in the clonidine group had urinary retention, while five patients in the ketamine and opioid groups did. There was only one study that reported that one child in the $1 \mu \mathrm{g} / \mathrm{kg}$ clonidine group and two children in the s-ketamine group suffered from hallucination. Although ketamine was considered neurotoxic, ${ }^{16}$ no included studies recorded any neurological impairment in our meta-analysis. In short, compared with other adjuncts, clonidine has a relatively higher safety margin with regard to adverse effects, which has been confirmed by an accidental 100 -fold overdosing trial without any major adverse effect. ${ }^{17}$

There was high heterogeneity in our meta-analysis concerning the duration of postoperative analgesia between clonidine and other adjuncts; the possible reasons for which were a combination of various doses of clonidine, addition of epinephrine, different pharmacology of other adjuncts, and diverse duration of LAs. Although Dobereiner et al ${ }^{18}$ have demonstrated that bupivacaine, levobupivacaine, and ropivacaine had equivalent efficacy when used in comparable doses, the heterogeneity between LAs could not be ignored. The studies in our meta-analysis were complex as presented because disparate types of combinations and single-factor subgroup analyses seem insufficient to explain this extremely high heterogeneity. Thus, we conducted a meta-regression to find the possible cause. However, the factors we hypothesized before could not explain the heterogeneity either.

\section{Limitations}

The limitations of our review are mainly owing to the methodological issues. First, high heterogeneity was not found in our meta-analysis. As such, the results evaluating the efficacy and adverse effects of clonidine versus other adjuncts may be influenced. Second, although we initially classified patients as those who underwent caudal, spinal, and epidural anesthesia, the patients with accessed data in our study were all finally under caudal anesthesia. Thus, the results could only demonstrate the efficacy and adverse effect of clonidine in caudal block, and hence, further studies are needed. Third, as the pain assessments in our meta-analysis varied, although a Cochrane review considering different assessments could be recognized as equivalent in terms of pain, the observer between parents and medical personnel may still influence the results.

\section{Conclusion}

Our meta-analysis and meta-regression suggested that clonidine, when compared with other adjuncts in neuraxial block, demonstrated a prolonged duration of postoperative analgesia with a lowered incidence of adverse effects. However, these results were limited by the high heterogeneity. Further largescale, multicenter, prospective, double-blinded RCTs are needed to validate our results.

\section{Disclosure}

The authors report no conflicts of interest in this work.

\section{References}

1. Association of Paediatric Anaesthetists of Great Britain and Ireland. Good practice in postoperative and procedural pain management, 2nd edition. Paediatr Anaesth. 2012;22(suppl 1):1-79.

2. Balent E, Edwards M, Lustik M, Martin P. Caudal anesthesia with sedation for inguinal hernia repair in high risk neonates. J Pediatr Surg. 2014;49(8):1304-1307.

3. Nishina K, Mikawa K, Shiga M, Obara H. Clonidine in paediatric anaesthesia. Paediatr Anaesth. 1999;9:187-202.

4. Petrova B, Gavrillova N, Koceva S, Boyadjieva S, Yaneva D. Caudal clonidine for postoperative analgesia in children aged 1 month -12 years undergoing subumbilical surgery. [Bulgarian]. Anaesthesiol Intensive Care. 2008;35:12-17.

5. López T, Sanchez FJ, Garzon JC, Muriel C. Spinal anesthesia in pediatric patients. Minerva Anestesiol. 2012;78(1):78-87.

6. Hozo SP, Djulbegovic B, Hozo I. Estimating the mean and variance from the median, range, and the size of a sample. BMC Med Res Methodol. 2005;5:13

7. Standing JF, Savage I, Pritchard D, Waddington M. Diclofenac for acute pain in children. Cochrane Database Syst Rev. 2009;(4):Cd005538. 
8. Constant I, Gall O, Gouyet L, Chauvin M, Murat I. Addition of clonidine or fentanyl to local anaesthetics prolongs the duration of surgical analgesia after single shot caudal block in children. Br JAnaesth. 1998;80:294-298.

9. Fernandes ML, Pires KC, Tiburcio MA, Gomez RS. Caudal bupivacaine supplemented with morphine or clonidine, or supplemented with morphine plus clonidine in children undergoing infra-umbilical urological and genital procedures: a prospective, randomized and double-blind study. J Anesth. 2012;26(2):213-218.

10. Schnabel A, Poepping DM, Pogatzki-Zahn EM, Zahn PK. Efficacy and safety of clonidine as additive for caudal regional anesthesia: a quantitative systematic review of randomized controlled trials. Paediatr Anaesth. 2011;21(12):1219-1230.

11. Popping DM, Elia N, Marret E, Wenk M, Tramer MR. Clonidine as an adjuvant to local anesthetics for peripheral nerve and plexus blocks: a meta-analysis of randomized trials. Anesthesiology. 2009;111(2):406-415.

12. Paul S, Bhattacharjee D, Nayek S, Chatterjee N, Sinha N. Efficacy of caudal bupivacaine alone or in combination with clonidine or neostigmine for postoperative analgesia in paediatric patients undergoing elective herniotomy. Pharmacologyonline. 2010;1:926-932.

13. Ansermino M, Basu R, Vandebeek C, Montgomery C. Nonopioid additives to local anaesthetics for caudal blockade in children: a systematic review. Paediatr Anaesth. 2003;13:561-573.

14. Breschan C, Krumpholz R, Likar R, Kraschl R, Schalk HV. Can a dose of 2 microg. $\mathrm{kg}(-1)$ caudal clonidine cause respiratory depression in neonates? Paediatr Anaesth. 1999;9(1):81-83.

15. Bouchut JC, Dubois R, Godard J. Clonidine in preterm-infant caudal anesthesia may be responsible for postoperative apnea. Reg Anesth Pain Med. 2001;26(1):83-85.

16. Lonnqvist PA, Walker SM. Ketamine as an adjunct to caudal block in neonates and infants: is it time to re-evaluate? Br JAnaesth. 2012;109(2): $138-140$.

17. Meyer C, Cambray R. One hundred times the intended dose of caudal clonidine in three pediatric patients. Paediatr Anaesth. 2008;18(9): 888-890.

18. Dobereiner EF, Cox RG, Ewen A, Lardner DR. Evidence-based clinical update: which local anesthetic drug for pediatric caudal block provides optimal efficacy with the fewest side effects? Can J Anaesth. 2010;57(12):1102-1110.

19. Ahuja S, Aggarwal M, Joshi N, Chaudhry S, Madhu SV. Efficacy of Caudal Clonidine and Fentanyl on Analgesia, Neuroendocrine Stress Response and Emergence Agitation in Children Undergoing Lower Abdominal Surgeries Under General Anaesthesia with Sevoflurane. JCDR. 2015;9:Uc01-05.
20. Akbas M, Akbas H, Yegin A, Sahin N, Titiz T. Comparison of the effects of clonidine and ketamine added to ropivacaine on stress hormone levels and the duration of caudal analgesia. Paediatr Anaesth. 2005: 580-585.

21. Batra Y, Rakesh S, Panda N, Lokesh V, Subramanyam R. Intrathecal clonidine decreases propofol sedation requirements during spinal anesthesia in infants. Paediatr Anaesth. 2010:625-632.

22. El-Hennawy AM, Abd-Elwahab AM, Abd-Elmaksoud AM, E1Ozairy HS, Boulis SR. Addition of clonidine or dexmedetomidine to bupivacaine prolongs caudal analgesia in children. Br J Anaesth. 2009; 103:268-274.

23. Jamali S, Monin S, Begon C, Dubousset AM, Ecoffey C. Clonidine in pediatric caudal anesthesia. Anesth Analg. 1994;78:663-666.

24. Khatavkar S, Lonkar S, Panchal P, Thatte W, Nagendra S, Tewari D. The efficacy of ropivacaine-fentanyl versus ropivacaine-clonidine for preemptive caudal anesthesia in children. Anaesthesia, Pain and Intensive Care. 2016:54-58.

25. Ribeiro Jr OD, de Abreu LC, Valenti VE, et al. Comparison between S-ketamine and clonidine in caudal analgesia. African Journal of Pharmacy and Pharmacology. 2011;5:2598-2604.

26. Sanwatsarkar S, Kapur S, Saxena D, Yadav G, Khan NN. Comparative study of caudal clonidine and midazolam added to bupivacaine during infra-umbilical surgeries in children. J Anaesthesiol Clin Pharmacol. 2017;33:241-247.

27. Shukla BU, Prabhakar T, Malhotra K. Postoperative analgesia in children when using clonidine or fentanyl with ropivacaine given caudally. J Anaesthesiol Clin Pharmacol. 2011;27:205-210.

28. Singh J, Shah R, Vaidya N, Mahato P, Shrestha S, Shrestha B. Comparison of ketamine, fentanyl and clonidine as an adjuvant during bupivacaine caudal anaesthesia in paediatric patients. Kathmandu Univ Med J (KUMJ). 2012:25-29.

29. Singh R, Kumar N, Singh P. Randomized controlled trial comparing morphine or clonidine with bupivacaine for caudal analgesia in children undergoing upper abdominal surgery. Br J Anaesth. 2011;106: 96-100.

30. Sinha C, Kumar B, Bhadani UK, Kumar A, Kumar A, Ranjan A. A comparison of dexamethasone and clonidine as an adjuvant for caudal blocks in pediatric urogenital surgeries. Anesth Essays Res. 2016;10: $585-590$.

31. Vetter T, Carvallo D, Johnson J, Mazurek M, Presson R. A comparison of single-dose caudal clonidine, morphine, or hydromorphone combined with ropivacaine in pediatric patients undergoing ureteral reimplantation. Anesth Analg. 2007:1356-1363.
Journal of Pain Research

\section{Publish your work in this journal}

The Journal of Pain Research is an international, peer reviewed, open access, online journal that welcomes laboratory and clinical findings in the fields of pain research and the prevention and management of pain. Original research, reviews, symposium reports, hypothesis formation and commentaries are all considered for publication.

\section{Dovepress}

The manuscript management system is completely online and includes a very quick and fair peer-review system, which is all easy to use. Visit http://www.dovepress.com/testimonials.php to read real quotes from published authors. 